\title{
SUMISIÓN DE LAS PARTES A LOS TRIBUNALES BELGAS EN EL MARCO DE UN CONTRATO INTERNACIONAL DE AGENCIA COMERCIAL: COMENTARIO A LA SENTENCIA DE LA AUDIENCIA PROVINCIAL DE BARCELONA (SECCIÓN 1 $1^{\mathrm{a}}$ ) DE 21 DE DICIEMBRE DE 2018
}

\section{SUBMISSION OF THE PARTS TO THE BELGIEN TRIBUNALS ABOUT THE INTERNATIONAL AGENCY AGREEMENTS: COMMENTS ABOUT THE JUDGEMENT ISSUED BY THE AUDIENCIA PROVINCIAL DE BARCELONA ON 21 DECEMBER 2018}

\author{
Hilda Aguilar Grieder \\ Profesora Titular de Derecho internacional privado \\ Universidad de Huelva \\ ORCID ID: 0000-0002-3138-8904
}

Recibido: 17.06.2019 / Aceptado: 05.07.2019

DOI: https://doi.org/10.20318/cdt.2019.4966

Resumen: El presente estudio analiza un problema frecuente de competencial judicial internacional que se plantea en el marco de los contratos internacionales de agencia comercial.

Palabras clave: Unión Europea, Derecho Internacional Privado, competencia judicial internacional, sumisión expresa, contratos internacionales de agencia comercial.

Abstract: This study analyses an international jurisdiction problem which arises frecuently in the frame of international agency agreements.

Keywords: European Union, Private International Law, international jurisdiction, jurisdiction clauses, international agency agreements.

Sumario: I. Consideraciones introductorias. II. Antecedentes de hecho. III. Eficacia de las cláusulas de elección de foro a favor de Tribunales de Estados miembros de la Unión Europea en el marco de los contratos internacionales de agencia comercial. 1. Marco normativo. 2. Jerarquización de los foros de competencia judicial internacional en el seno del Reglamento "Bruselas I"/"Bruselas I bis". 3. Alcance de la Disposición Adicional de la Ley 12/1992, de 27 de mayo, sobre el contrato de agencia.

\section{Consideraciones introductorias}

1. La sentencia de la Audiencia Provincial de Barcelona (Sección 1 ${ }^{\mathrm{a}}$ ) de 21 de diciembre de 2018 (sentencia núm. 717/2018) , objeto de comentario en el presente estudio, trae causa del recurso de apelación interpuesto contra la sentencia dictada, el 5 de mayo de 2016, por el Juzgado de Primera Instancia

${ }^{1}$ JUR/2019/15121. 
$\mathrm{n}^{\mathrm{o}} 22$ de Barcelona. Desde el punto de vista del Derecho internacional privado, en ambas sentencias se plantea fundamentalmente un problema de competencia judicial internacional ${ }^{2}$, que tanto la sentencia del Juzgado de Primera Instancia de Barcelona, como la sentencia de la Audiencia Provincial de Barcelona, resuelven del mismo modo.

2. En concreto, detrás de la problemática planteada por las mentadas sentencias de Barcelona subyace el alcance de las cláusulas de elección de foro, a favor de Tribunales de Estados miembros de la Unión Europea, en los litigios planteados ante los Tribunales españoles, entre las dos partes de un contrato internacional de agencia comercial, esto es, entre el principal y el agente comercial. Esta cuestión está íntimamente relacionada con la relativa a la naturaleza y el alcance de la controvertida Disposición Adicional de la Ley 12/1992, de 27 de mayo, sobre el contrato de agencia ${ }^{3}$. Por virtud de dicha Disposición Adicional, la "competencia para el conocimiento de las acciones derivadas del contrato de agencia corresponderá al Juez del domicilio del agente, siendo nulo cualquier pacto en contrario".

\section{Antecedentes de hecho}

3. La sentencia objeto de comentario versa sobre un contrato de agencia comercial (denominado como "contrato de servicios") suscrito, el 25 de julio de 2012, entre dos sociedades domiciliadas en distintos Estados miembros de la Unión Europea: en España, el agente comercial y, en Bélgica, el principal.

4. La entidad Transacciones Alimentarias Europeas (en lo sucesivo, TAE), que actúa en el contrato como agente comercial (tal como reconoce la Audiencia Provincial de Barcelona, a dicha entidad le encomendaron por contrato desarrollar las funciones propias de un agente comercial), interpone una demanda ante los Tribunales españoles (Juzgado de Primera Instancia/Sección $1^{\text {a }}$ de la Audiencia Provincial de Barcelona), contra la sociedad NV Gourmand (principal), por virtud de la cual solicita una indemnización por clientela, así como el pago de determinadas facturas que quedaban pendientes de abonar (junto con los intereses legales y las costas procesales).

5. El contrato de agencia comercial era de duración indefinida y de naturaleza exclusiva. Por virtud del referido contrato de agencia, el principal pretendía incrementar su clientela en España y Portugal, siendo éste, por tanto, el mercado afectado. El objeto del contrato consistía en que la entidad TAE, además de proporcionar determinados servicios administrativos, promocionase en España la marca de la sociedad NV Gourmand y ampliase su cartera de clientes, que hasta el momento de formalizar el contrato sólo constaba de cuatro sociedades (tres en España y una en Portugal), promoviendo y potenciando las ventas de NV Gourmand, en los susodichos países, siguiendo las instrucciones del principal.

6. Como viene siendo habitual en la práctica, por medio de una comunicación, que tuvo lugar el 19 de mayo de 2014, el principal resolvió unilateralmente el contrato de prestación de servicios, esto es, el contrato de agencia existente entre ambas entidades; alegando no haber cumplido el agente, en relación con el mercado español, con los objetivos marcados, ya que el nivel de ventas en España había sido inferior al inicialmente previsto. En la inmensa mayoría de las ocasiones, en esta categoría contractual, la litigiosidad entre el principal y el agente comercial tiene lugar tras la terminación del contrato; momento en el cual el agente comercial (que suele ser el demandante en prácticamente todos los su-

\footnotetext{
${ }^{2}$ En relación con la problemática de Derecho aplicable planteada, en el seno de los contratos internacionales de agencia comercial (la cual no ha sido objeto de debate en las sentencias a las que nos acabamos de referir), vid., por todos, H. AGUILAR GRIEDER, "El impacto del Reglamento 'Roma I' en el contrato internacional de agencia”, Cuadernos de Derecho Transnacional, 2011, vol. 3, núm. 1, pp. 24-46; id., La protección del agente en el Derecho comercial europeo, Colección "El Derecho de la globalización”, núm. 14, Colex, Madrid, 2007.

${ }^{3}$ BOE, de 29 de mayo de 1992, núm. 129.
} 
puestos y la parte más debilitada de la relación contractual) interpone una demanda, contra el principal, solicitándole una indemnización por clientela por los gastos en los cuales ha tenido que incurrir para llevar a cabo su cometido.

7. La parte demandada, esto es, el principal, formuló declinatoria por falta de jurisdicción y de competencia territorial, con suspensión del plazo de contestación a la demanda. La parte actora, es decir, el agente comercial, se opuso a la declinatoria formulada por la demandada. Cabe destacar que el Ministerio Fiscal informó en el sentido de estimar la falta de jurisdicción y de competencia territorial del Juzgado.

El Juzgado de Primera Instancia núm. 22 de Barcelona, por auto dictado el 19 de diciembre de 2014, acordó desestimar la declinatoria presentada por la sociedad NV Gourmand (principal); por lo que dicha sociedad formuló un recurso de reposición contra el referido auto, que fue asimismo desestimado.

8. La sociedad NV Gourmand (principal) se opuso a la demanda formulada por TAE (agente comercial), alegando, básicamente, que no procedía indemnización alguna por clientela y que no se adeudaban ninguna de las facturas reclamadas. La sentencia dictada en primera instancia, que calificó al contrato suscrito entre las partes como de agencia, estimó parcialmente la demanda formulada por TAE, desestimando la indemnización por clientela y estimando parcialmente la reclamación relativa a determinadas facturas.

Frente a dicha resolución, la parte actora (TAE) formuló un recurso de apelación (alegando, fundamentalmente, error en la valoración de ciertas pruebas [sobre el incremento de clientela, ciertas facturas, etc.]), ante la Sección $1^{\text {a }}$ de la Audiencia Provincial de Barcelona (cuya sentencia es objeto del presente comentario). La parte demandada (NV Gourmand) se opuso al recurso de apelación formulado por TAE, a la par que impugnó la sentencia dictada alegando, muy especialmente, la falta de jurisdicción y de competencia de los Tribunales españoles, para conocer del litigio, al existir una cláusula de sumisión expresa a los Tribunales y a la normativa belga; cuestión ésta que es objeto del presente comentario. La parte actora formuló oposición a la referida impugnación.

9. En relación con la cuestión debatida en el presente estudio, es preciso tener en cuenta que el contrato internacional de agencia, objeto de la sentencia, contenía en su seno, además de una cláusula de elección de ley a favor de la legislación belga, una cláusula de elección de foro a favor de los Tribunales belgas (de Kortrijk): el "presente contrato se regirá por las leyes de Bélgica y se interpretará con sujeción a las mismas. Las partes acuerdan y se someten con carácter irrevocable a la jurisdicción exclusiva de los juzgados y tribunales de Kortrijk en relación con cualquier acción, demanda o cualquier otro procedimiento relativo a la validez, interpretación, ámbito de aplicación, contenido, ejecución o resolución del presente contrato". Dicha cláusula, muy habitual en la práctica internacional, figuraba bajo la rúbrica "Ley aplicable y jurisdicción competente".

10. El Juzgado de Primera Instancia núm. 22 de Barcelona desestimó la declinatoria de jurisdicción planteada, por la que se hacía valer la referida cláusula de elección de foro contenida en el contrato de agencia, por considerar de aplicación la polémica Disposición Adicional, de la ya citada Ley 12/1992 sobre el contrato de agencia, anteriormente transcrita; añadiendo referencias sobre la nulidad de aquellas cláusulas contractuales en las relaciones jurídicas en que se presume un desequilibrio entre las partes. La Sección $1^{\text {a }}$ de la Audiencia Provincial de Barcelona señala, con base fundamentalmente en la susodicha Disposición Adicional de la Ley española de agencia, que la conclusión alcanzada, en primera instancia, "sobre la jurisdicción de los Tribunales españoles se estima acorde y ajustada a derecho".

En el siguiente apartado nos proponemos analizar si la argumentación utilizada por la Sección $1^{\text {a }}$ de la Audiencia Provincial de Barcelona, en la sentencia de 21 de diciembre de 2018, fue o no la correcta en lo que atañe al referido problema planteado en materia de competencia judicial internacional. 


\section{Eficacia de las cláusulas de elección de foro a favor de Tribunales de Estados miembros de la Unión Europea en el marco de los contratos internacionales de agencia comercial}

\section{Marco normativo}

11. En relación con los contratos internacionales de agencia comercial, se vislumbra una acentuada concurrencia normativa, ya que es uno de los sectores de la contratación en los que se produce una concurrencia entre los Reglamentos europeos de Derecho internacional privado que regulan los contratos internacionales (tanto en sede de Derecho aplicable como en la esfera del Derecho procesal civil internacional) y una Directiva europea sectorial. En este contexto, es preciso distinguir, pues, un marco normativo general y uno específico.

12. En lo que atañe a la problemática relativa a la competencia judicial internacional, el marco normativo general está formado, en la actualidad, por el Reglamento (UE) núm. 1215/2012 del Parlamento Europeo y del Consejo, de 12 de diciembre de 2012, relativo a la competencia judicial, el reconocimiento y la ejecución de resoluciones judiciales en materia civil y mercantil (en lo sucesivo, el Reglamento "Bruselas I bis") ${ }^{4}$. Dicho Reglamento sustituye al Reglamento (CE) núm. 44/2001, del Consejo, de 22 de diciembre de 2000, relativo a la competencia judicial, el reconocimiento y la ejecución de resoluciones judiciales en materia civil y mercantil (en adelante, el Reglamento "Bruselas I") 5 .

Tal como pone de manifiesto la sentencia de la Audiencia Provincial de Barcelona, de 21 de diciembre de 2018, el supuesto de hecho planteado en el caso de autos entra dentro del ámbito de aplicación temporal del Reglamento "Bruselas I", y no del Reglamento "Bruselas I bis" (que es el actualmente vigente), ya que la demanda se presentó, ante el Juzgado de Primera Instancia núm. 22 de Barcelona, con anterioridad al 10 de enero del año 2015. Dicha afirmación de la Audiencia Provincial es correcta, ya que el supuesto planteado entra dentro del ámbito de aplicación material, temporal y espacial del Reglamento "Bruselas I". Si la demanda llega a ser posterior al 10 de enero de 2015, hubiese resultado aplicable el Reglamento "Bruselas I bis", conforme al cual se resuelve del mismo modo la problemática de competencia judicial internacional objeto del presente comentario.

13. El marco normativo específico, en la categoría contractual objeto de análisis, está formado por la Directiva 86/653/CEE del Consejo, de 18 de diciembre de 1986, relativa a la coordinación de los derechos de los Estados miembros en lo referente a los agentes comerciales independientes ${ }^{6}$ (en lo sucesivo, Directiva de agencia). Dicha Directiva, que es considerada como una Directiva de mínimos y que regula la relación jurídica existente entre el principal y el agente comercial, ha sido objeto de transposición a todos los ordenamientos jurídicos internos de los Estados miembros de la Unión Europea. De los Considerandos de la mencionada Directiva se desprende que la misma persigue una doble finalidad: por un lado, la protección del mercado interior y, por otro lado, la protección del agente comercial en tanto que parte débil de la relación litigiosa. Dicha finalidad tuitiva subyace igualmente, por consiguiente, detrás de todas las Leyes nacionales de transposición de la misma, es decir, detrás de todas las Leyes de agencia de los Estados miembros de la Unión Europea. La transposición de la Directiva de agencia, al ordenamiento jurídico español, se llevó a cabo por la anteriormente mentada Ley 12/1992 sobre el contrato de agencia.

14. La aplicación de la Directiva de agencia al supuesto de autos no plantea ninguna duda, ya que, aunque la misma guarda silencio sobre su ámbito de aplicación espacial, el agente comercial realiza su actividad profesional en el mercado de la Unión Europea (en concreto, en España y Portugal), por lo que se cumple el criterio consagrado por la controvertida sentencia del TJCE de 9 de noviembre de 2000

${ }^{4}$ DOUE, de 20 de diciembre de 2012, núm. L 351; modificado por el Reglamento 542/2014: DOUE, de 29 de mayo de 2014, núm. L 163.

${ }^{5}$ DOCE, de16 de enero de 2001, núm. L 12.

${ }^{6}$ DOCE, de 31 de diciembre de 1986, núm. L 382. 
(asunto Ingmar) $)^{7}$. Ello implica que se apliquen las disposiciones imperativas (tanto las expresa como las implícitamente imperativas) de la Directiva de agencia, tal como hayan sido transpuestas por los ordenamientos jurídicos internos de los Estados miembros de la Unión Europea. La aplicación de las susodichas disposiciones imperativas constituye una salvaguarda del respeto de un nivel de protección mínimo, del agente comercial, cuando el mercado afectado sea el territorio de la Unión Europea, como es el caso.

15. La Audiencia Provincial de Barcelona, en su sentencia de 21 de diciembre de 2018, expone correctamente el marco normativo aplicable al supuesto de autos, tanto el general como el específico. A mi modo de ver, en lo que no acierta la Audiencia Provincial es en la interpretación y aplicación de la normativa vigente, tal como vamos a pasar a exponer a continuación, lo cual acarrea que el resultado alcanzado, en la problemática relativa a la competencia judicial internacional, sea incorrecto.

\section{Jerarquización de los foros de competencia judicial internacional en el seno del Reglamento "Bruselas I"/"Bruselas I bis"}

16. De hecho, la Audiencia Provincial no tiene en cuenta la jerarquización de los foros de competencia judicial internacional, que caracteriza tanto al Reglamento "Bruselas I" (el aplicable al supuesto de autos) como al Reglamento "Bruselas I bis" (el actualmente vigente). Ello es clave para aplicar correctamente los susodichos Reglamentos. Como es sabido, ambos Reglamentos europeos, de Derecho procesal civil internacional, contienen una estructura jerarquizada de los foros de competencia judicial internacional que consagran: competencias exclusivas (primer nivel de jerarquía), sumisión tácita (segundo rango jerárquico), sumisión expresa (tercer nivel de jerarquía) y, en el último rango o escalón jerárquico (lo cual implica que, en defecto de los foros anteriores, el actor pueda elegir entre uno u otro), concurre tanto el foro del domicilio del demandado como los foros especiales por razón de la materia (en nuestro caso, el foro especial en materia contractual [que es el aplicable a la generalidad de los contratos internacionales, esto es, a todas las categorías contractuales que no quedan sometidas al régimen especial de competencia judicial internacional] $)^{8}$.

17. Dicha jerarquización de foros no ha sido tenida en cuenta por la Sección $1^{\text {a }}$ de la Audiencia Provincial de Barcelona en la sentencia objeto de comentario, la cual mezcla los foros de competencia judicial internacional del Reglamento "Bruselas I" como si estuviesen situados al mismo nivel, esto es, en el mismo plano jerárquico. De hecho, la sentencia alude tanto al foro de la sumisión expresa (que recordemos que juega a favor de los Tribunales belgas), como al foro del domicilio del demandado, esto es, del principal (el cual, como anteriormente pusimos de manifiesto, también se encuentra en Bélgica), como si se encontrasen situados en el mismo nivel de jerarquía, cuando ello es claramente erróneo. Ello pone de manifiesto una confusión, de la Audiencia Provincial, en cuanto al funcionamiento de los foros de competencia judicial internacional del Reglamento "Bruselas I" se refiere. Sorprende que con este nivel de confusión, la Audiencia no haya hecho alusión al foro especial en materia contractual del art. 5.1b) del Reglamento "Bruselas I", ya que, de los datos del supuesto de autos parece desprenderse que la actividad principal del agente comercial se llevaba a cabo en el mercado español.

\section{Alcance de la Disposición Adicional de la Ley 12/1992, de 27 de mayo, sobre el contrato de agencia}

18. Pese a que la Sección $1^{\text {a }}$ de la Audiencia Provincial de Barcelona reconoce, en la sentencia comentada, que conforme a ambos foros de competencia judicial internacional del Reglamento "Bruselas I" debería de declararse la competencia de los Tribunales belgas; expone, a continuación, que, "no obstante, concurren otros elementos de juicio a considerar que nos llevarán finalmente a concluir que debe mantenerse la jurisdicción de los tribunales españoles".

\footnotetext{
${ }^{7}$ Asunto C-381/98.

${ }^{8}$ Por lo que a dicha estructura jerarquizada se refiere, vid., por todos, H. Agullar Grieder, Pilares fundamentales del Derecho internacional privado europeo, Servicio de Publicaciones de la Universidad de Huelva, núm. 166, 2018, pp. 73-97.
} 
En concreto, la sentencia de 21 de diciembre de 2018 considera que, teniendo en cuenta la imperatividad de los preceptos de la Ley 12/1992 sobre el contrato de agencia (salvo expresa previsión en contrario), conforme a la Disposición Adicional de dicha Ley (la Audiencia señala que hay que considerar indisponible la regla de competencia que la misma establece), son competentes para conocer del litigio planteado, no los Tribunales belgas, como se deriva de la aplicación al supuesto de autos del art. 23 del Reglamento "Bruselas I" (que constituye el antecedente directo del art. 25 del Reglamento "Bruselas I bis" [que recordemos que no es el aplicable al supuesto enjuiciado]), sino los Tribunales españoles. Esta afirmación precisa examinar la naturaleza y el alcance de la referida Disposición Adicional de la Ley española sobre el contrato de agencia, la cual, como anteriormente pusimos de manifiesto, otorga competencia, para solventar los litigios derivados de dicha categoría contractual, al "Juez del domicilio del agente, siendo nulo cualquier pacto en contrario".

En suma, la Ley española sobre el contrato de agencia prevé, en su Disposición Adicional, un foro de competencia imperativo especial para esta concreta categoría contractual (el foro del lugar del domicilio del agente comercial), tendente a facilitar al agente el acceso a la jurisdicción, cuyo concreto alcance es necesario delimitar, ya que de ello va a depender la validez o no de las cláusulas de elección de foro en los litigios internacionales entre principal y agente comercial. En relación con la referida Disposición adicional, para resolver el supuesto de autos, es necesario precisar si la regla de competencia prevista por la Disposición Adicional de la legislación española de agencia es una norma de competencia judicial internacional de origen comunitario (europeo), una norma de competencia judicial internacional de producción interna o una mera norma de competencia territorial interna.

19. La cuestión debatida va a depender, pues, de si la norma de competencia que establece la polémica Disposición Adicional, de la Ley 12/1992, es o no una norma de competencia judicial internacional de origen comunitario (europeo). En relación con esta cuestión, es preciso tener presente que la Directiva de agencia únicamente contiene normas materiales (expresamente imperativas, implícitamente imperativas y dispositivas), pero carece de normas de Derecho internacional privado, ni de Derecho aplicable (la misma es tan parca que incluso guarda silencio sobre su ámbito de aplicación espacial ${ }^{9}$ ), ni de competencia judicial internacional.

Tampoco existe ningún indicio que haga pensar que la Directiva de agencia de 1986 contenga una norma implícita de competencia judicial internacional. Pero, además, en el supuesto en que la contuviese, ésta no tendría nada que ver con el tenor de la Disposición Adicional de la legislación española de agencia, sino que lo que previsiblemente haría sería impedir que el nivel de protección mínimo en favor del agente comercial, impuesto por las disposiciones imperativas de la Directiva de agencia, pudiera defraudarse, de un modo indirecto, por la vía de las cláusulas de elección de foro.

Por lo tanto, la norma de competencia, de la señalada Disposición Adicional de la Ley 12/1992, representa una novedad que excede del contenido de la Directiva de agencia y que implica una aportación propia (como norma exclusiva de Derecho interno) que carece de virtualidad para ser aplicada a través del art. 67 del Reglamento "Bruselas I"/Reglamento "Bruselas I bis".

En suma, tal como ha señalado la jurisprudencia española (entre ellas, la relevante sentencia de la Audiencia Provincial de Santa Cruz de Tenerife [Sección 1 ${ }^{\mathrm{a}}$ ] de 10 de septiembre de $2001^{10}$, así como la sentencia de la Audiencia Provincial de Castellón [Sección $1^{\mathrm{a}}$ ] de 10 de febrero de $2003^{11}$ ), la norma contenida en la referida Disposición Adicional no es una norma de competencia judicial internacional de origen comunitario (europeo), por lo que no tiene cabida dentro del art. 67 del Reglamento "Bruselas I" 12

\footnotetext{
${ }^{9}$ Ello no sintoniza con la generalidad de las Directivas europeas sectoriales, las cuales suelen manifestarse por lo que a esta cuestión se refiere.

${ }^{10}$ Aranzadi Civil, 2002, núm. 356; REDI, 2002, vol. LIV, núm. 1, pp. 378-381.

11 Aranzadi Civil, 2003, núm. 354.

${ }^{12}$ Por virtud del art. 67 del Reglamento "Bruselas I", que es el aplicable al supuesto de autos debido a la fecha de la presentación de la demanda ante el Juzgado de Primera Instancia núm. 22 de Barcelona (anterior al 10 de enero de 2015), el señalado Reglamento "no prejuzgará la aplicación de las disposiciones que, en materias particulares, regularen la competencia judicial, (...), contenidas en los actos comunitarios o en las legislaciones nacionales armonizadas en ejecución de dichos actos", esto es, en las legislaciones nacionales, de transposición de las Directivas europeas sectoriales, elaboradas por los Estados miembros de la Unión Europea. Por lo tanto, al igual que acontece con otros Reglamentos europeos de Derecho internacional privado,
} 
(cuyo contenido coincide con el del art. 67 del Reglamento "Bruselas I bis"). De este modo, la norma de competencia, consagrada por la Disposición Adicional de la Ley 12/1992, queda fuera del alcance del principio de primacía del Derecho comunitario (esto es, del Derecho de la Unión Europea) y, por consiguiente, no prima sobre la norma contenida en el art. 23 del Reglamento "Bruselas I", conforme a la cual la competencia judicial internacional corresponde, en el supuesto de autos, a los Tribunales belgas.

20. Por otro lado, tal como ha recalcado la jurisprudencia española anteriormente citada, con base en un argumento sistemático, la norma de competencia contenida en la señalada Disposición Adicional tampoco es una norma de competencia judicial internacional de producción interna, es decir, del sistema autónomo español (el cual, como conocemos, tiene carácter subsidiario, lo cual implica que únicamente pueda entrar en juego en defecto de instrumento internacional). De hecho, dicha norma, además de no estar integrada en el marco normativo que regula la extensión y límites de la jurisdicción española, no contiene ninguna alusión al elemento internacional que haga pensar en su proyección a dicho ámbito; a diferencia de lo que acontece, por ejemplo, con el art. 27 de la Ley belga, de 13 de abril de 1995 , sobre el contrato de agencia, que sí que hace expresa mención de su carácter internacional ${ }^{13}$. Dicha norma tiene, pues, el carácter de norma de competencia judicial internacional de origen, no comunitario (europeo), sino interno.

Por ello, sorprende que la Audiencia Provincial de Barcelona asimile el art. 27 de la legislación belga de agencia con la Disposición Adicional de la legislación española de agencia, ya que, como hemos señalado, no presentan el mismo carácter (la primera es una norma de competencia judicial internacional de origen interno y la segunda es una norma de competencia territorial interna). La comparativa llevada a cabo por la Audiencia Provincial, además de ser errónea, no aporta nada al supuesto de autos, ya que ni siquiera el art. 27 de la legislación belga de agencia tiene la consideración de norma de competencia judicial internacional de origen comunitario (europeo).

La Audiencia Provincial, en aras de reforzar su criterio interpretativo, trae a colación la conclusión de la sentencia del TJUE (Sala 3 ${ }^{\mathrm{a}}$ ) de 17 de octubre de 2013 (asunto Unamar) ${ }^{14}$; asunto en el cual conocían los Tribunales belgas, pese a contener el contrato internacional de agencia comercial una cláusula de sumisión expresa a los Tribunales búlgaros (y una cláusula de elección de ley a favor de la normativa búlgara). La referencia a dicha conclusión para fortalecer la postura de la Audiencia en torno a un problema de competencia judicial internacional, además de implicar una confusión o mezcla entre el susodicho sector y el del Derecho aplicable, tampoco aporta nada, ya que el pronunciamiento referido alude al sector del Derecho aplicable, en concreto, al alcance de las "leyes de policía".

Del mismo modo, sorprende que la Audiencia Provincial recurra, en ocasiones, en aras de tratar de reforzar su criterio interpretativo, al Reglamento "Bruselas I bis", cuando la misma reconoce que "debe aplicarse al supuesto de autos" el Reglamento "Bruselas I".

21. En suma, la norma de competencia, contenida en la Disposición Adicional de la legislación española de agencia, no es una norma de competencia judicial internacional de origen internacional ni de producción interna, sino una mera norma de competencia territorial interna; lo cual implica que su operatividad sea muy reducida. Por lo tanto, la regla contenida en la Disposición adicional, de la legislación española de agencia, únicamente operará en los supuestos meramente internos y, en las situaciones privadas internacionales, cuando la jurisdicción española sea competente para conocer de un contrato internacional de agencia comercial y el agente comercial esté domiciliado en España (salvo que el foro de competencia judicial internacional que resulte aplicable esté llamado a actuar, al mismo tiempo, como

dichas normas gozan de primacía sobre las contenidas en el Reglamento "Bruselas I"/Reglamento "Bruselas I bis". Dicho precepto, que determina cuáles son las relaciones del Reglamento "Bruselas I" (o, en su caso, del Reglamento "Bruselas I bis") con otras disposiciones del Derecho de la Unión Europea, tiene como finalidad primordial permitir una mayor especialización de las soluciones.

${ }_{13}$ Por virtud del art. 27 de la legislación belga de agencia de 1995, salvo que resulte aplicable un Convenio internacional ratificado por Bélgica que establezca otra cosa, "toda actividad de un agente comercial que tenga su establecimiento principal en Bélgica se regirá por la ley belga y será de la competencia de los Tribunales belgas". Dicho precepto, que consagra una correlación entre forum-ius, alude expresamente, pues, a su carácter internacional, ya que habla de los "Tribunales belgas".

${ }^{14}$ Asunto C-184/12. 
foro de competencia territorial interna, como es el caso del foro especial en materia contractual del art. 5.1 del Reglamento "Bruselas I").

22. En conclusión, la confusión manifestada por la Sección $1^{\text {a }}$ de la Audiencia Provincial de Barcelona, en su sentencia de 21 de diciembre de 2018, en torno a ciertos aspectos básicos del sector de la competencia judicial internacional (que han quedado patentes en las líneas anteriores), la lleva a alcanzar una conclusión errónea en cuanto a esta problemática se refiere, al otorgar competencia judicial internacional a los órganos jurisdiccionales españoles, en lugar de a los Tribunales belgas (conforme al foro de competencia judicial internacional de la sumisión expresa del art. 23 del Reglamento "Bruselas I" [que era el aplicable al supuesto de autos por la argumentación anteriormente expuesta]), para conocer del litigio planteado entre TAE (agente comercial) y NV Gourmand (principal). 